\title{
Forestry Felling \& Cultivation Machine Modeling and Analysis
}

\author{
Zhanguo Wei, Zhongwei Wang and Zhuoxia Zhou \\ Centre South University of Forestry and Technology, Changsha, Hunan, China \\ jackwzg007@163.com,wangpmp@163.com,axgoal@hotmail.com
}

\begin{abstract}
The mathematical model of Forestry Felling \& Cultivation Machine Transmission System describes the relationship between chassis transmission system and dynamic property by mathematical expression. Models reflect the relationships among the composing units of chassis transmission system, each units variable quantities and external environment elements.

The mathematical model of Forestry Felling \& Cultivation Machine Transmission System must be built before testing the performance of machine chassis through computer simulation.

This paper mainly elaborates each composing unit of chassis dynamic transmission system and its mathematical models. Then, utilize MATLAB/ Simulink software to calculate and simulate its usability.
\end{abstract}

Keywords: tranmission system, simulation, dynamic

\section{Introduction}

This paper mainly use mathematical method in building mathematical models of each unit of WCFJ30-I Forestry Felling \& Cultivation Machine transmission system, then divides the system into separated independent composing units based on mathematical models. By operating MATLAB/Simulink software and adapting backward simulation methods, dynamic simulation models of each composing units of Forestry Felling \& Cultivation Machine transmission system can be formed. Thus, when input the chassis system paraments, the simulation of transmission system be triggered.

\section{Transmission System Structure of Felling \& Cultivation Machine}

According to the design scheme of WCFJ20-I Forestry Felling \& Cultivation Machine, the hydrodynamic transmission system is used in the chassis drive train.

The structure includes a diesel engine, a single-stage single-phase three-component type torque converter, a mechanical gearbox, a transmission shaft, a wet front and back drving axle and engineering tires, etc.

Hydrodynamic transmission system scheme of WCFJ30-I is shown in Figure 1.

The chassis transmission system is a complex system, establishing an accurate mathematical model is the key for an appropriate simulation analysis. Although refining a mathematical model and improving the accuracy of input parameters are the common methods, over refining a model will increase the amount of calculation and make it more complex, which will eventually affect the real time performance and generality of the model. Meanwhile, accurate input parameters excessively depend on the test preparation which is limited by the objective conditions. Most currently adopted modeling schemes aim to solve specific problems without affecting other factors and establish more neutral models.

Based on the WCFJ30-I Forestry Felling \& Cultivation Machine, this paper analysis the formation and transmission process of the power, which enable us to build the mathematical model of each composing unit. 


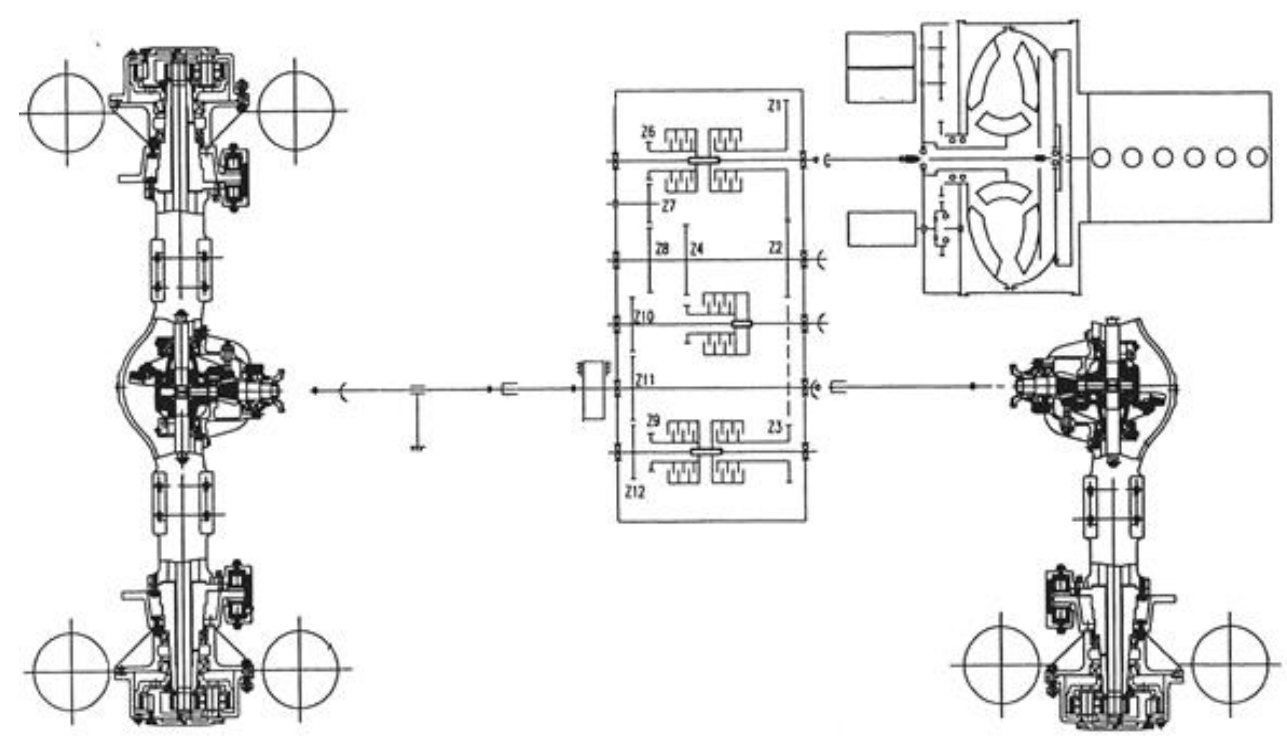

Figure 1. Hydrodynamic Transmission System Scheme of WCFJ30-I

\section{Felling \& Cultivation Machine Mathematics Modeling}

\subsection{Engine Mathematics Modeling}

Engine, which is the motive power output of chassis, its performance determines the whole drive performance of the machine. Thus, before making simulation analysis for the drive performance, right mathematical description for engine performance should have been built. There are two common methods for modeling engine: one is establish the connection between engine characteristics and input variable, which based on the theoretic calculation for thermodynamic cycle and the analysis for operational mechanism of the engine. This method is mainly applied in developing engine; the other is gathering steady-state experiment data of engine by practical testing at first, then establishing engine experimental model by looking up tables or fitting formulas. This method is widely used in engineering field out of its convenience and accuracy in modeling.

This paper establishes mathematical model of the diesel engine of Felling \& Cultivation Machine according to the establishment method of experimental model of engineering machines.

(1)Mathematical model of external characteristic for engine.

Engine torque of external characteristic of engine $T_{e}$ is expressed by the function of engine speed $\mathrm{n}$. So the polynomial expression of mathematical model for external characteristic of engine is (YU, 2000):

In formula:

$$
\begin{aligned}
k & =\frac{1}{k_{2}}(j+1)(j+2)(2 j 1) 1+i \\
T_{e} & =\sum_{j=0} a_{j} n^{j}
\end{aligned}
$$

$\mathrm{A}_{\mathrm{j}}$-polynomial coefficient,

K-polynomial degree.

In certain time intervals, engine bench test is conducted in the conditions of different throttling levels, Mathematical representation of discrete matrix for test point:

Engine torque: $\left[\mathrm{T}_{\mathrm{e}}\right]=\left[\mathrm{T}_{\mathrm{e} 1}, \mathrm{~T}_{\mathrm{e} 2}, \mathrm{~T}_{\mathrm{e} 3} \ldots \mathrm{T}_{\mathrm{en}}\right]$,

Engine speed: $\left[n_{e}\right]=\left[n_{e 1}, n_{e 2}, n_{e 3}, \ldots n_{e n}\right]$. 
(2) Mathematical model of universal characteristics for engine

When engine work under the stability condition, relationship between its specific fuel consumption rate and its speed and torque go by the name of Engine universal characteristics, Mathematical expression. ( Zeng. 2005)

In the formula:

$$
b_{e}=\sum_{j=0}^{s} \sum_{i=0}^{j} a_{k} T_{e}^{i} n_{e}^{j-1}
$$

$a_{k}-$ fitting coefficient, in which,

$k=\frac{1}{2}(j+1)(j+2)-j-1+i$

$\mathrm{S}$ - surface fitting order.

(3) Engine dynamics mathematical model

Mathematical expression for engine dynamics is shown as follow:

$$
I_{e} \omega=T_{e}-T_{a o}-T_{e o}
$$

In the formula:

$I_{e}-$ flywheel inertia $\left(\mathrm{kg} \cdot \mathrm{m}^{2}\right)$

$\omega-$ crankshaft speed $(\mathrm{rad} / \mathrm{s})$

$T_{a o} \quad$ - torque loss of accessories

$T_{e o} \quad$ - output torque of engine

Single-stage single-direction three-element torque converter is adopted in WCFJ30-I Felling \& Cultivation Machine.

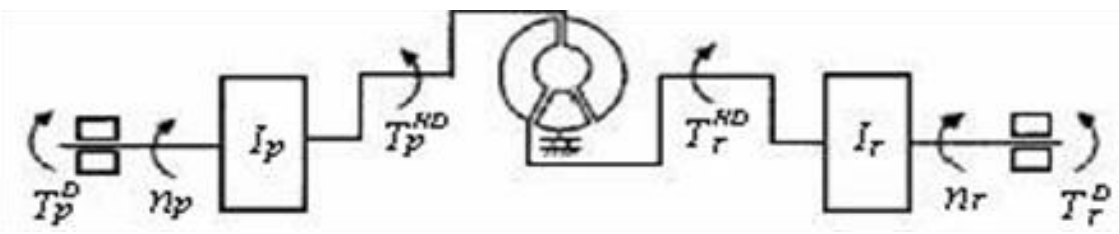

\section{Figure 2-1. Hydraulic Torque Converter Dynamic Model}

In figure, $T_{P}^{D}$ is pump impeller axis dynamic torque, $T_{p}^{H D}$ is pump impeller dynamic torque, $I_{p}$ is pump impeller equivalent rotary inertia, $n_{p}$ is pump impeller rotational speed, $T_{\tau}^{D}$ is turbine shaft dynamic torque in unsteady condition, $T_{\tau}^{H D}$ is turbine dynamic torque, $I_{\tau}$ is turbine equivalent rotary inertia, $n_{\tau}$ is rotational speed, hydraulic torque converter can be established based on this (Chang et. al., 2006):

$$
\left\{\begin{array}{l}
T_{p}^{D}=T_{p}^{H D}+I_{p} \frac{d n_{p}}{d t} \\
T_{\tau}^{D}=T_{\tau}^{H D}+I_{p} \frac{d n_{\tau}}{d t}
\end{array}\right.
$$

It can be known from the characteristics of hydraulic torque converter that,

$$
\left\{\begin{array}{l}
T_{p}^{H D}=\lambda_{p} \rho g n_{p}^{2} D^{5} \\
T_{\tau}^{H D}=K T_{p}^{H D} \\
n_{\tau}=i n_{p}
\end{array}\right\}
$$


In formula:

$\lambda_{p}:$ pump impeller dynamic torque coefficient

$\rho_{p}$ : operating fluid density

$\rho$ : circle ring diameter

$K \quad$ : dynamic torque converting ratio

i : transmission ratio

Two formulas constitute the mathematical model of hydraulic torque converter of Felling \& Cultivation Machine. In common place, regardless of significant deviation, steady characteristics of hydraulic torque converter can directly substitute for its dynamic one.

This paper mainly considers the moment of inertial generated by equivalent inertia of turbine. Under the current transmission ratio $i$, dynamic $\lambda_{p}$ and $K$ can be given by the initial performance curve of the hydraulic torque converter, which enable us to operate the simulation analysis as calculating the dynamic hydraulic torque of pump impeller and turbine. Meanwhile, the equivalent rotary inertia of pump impeller should ignored (Hrovat, D. 1985; Tsangarides, M.C. 1994).

\subsection{Gearbox Modeling}

Mathematical model of gearbox for forward path input shaft. (Randall Donn Senger, 1997):

$T_{g o}=\left(T_{g i n} \eta_{g}-T_{g i}\right) i_{g}$

In formula:

$\eta_{g}:$ transmission efficiency of gearbox.

Mathematical model of gearbox for backword path input shaft as follow:

$T_{g o}=\left(T_{g i n}-T_{g f}-T_{g i}\right) i_{g}$

In formula:

$\mathrm{T}_{\mathrm{go}}$ : gearbox output torque $(\mathrm{N} \cdot \mathrm{m})$;

$\mathrm{T}_{\text {gin }}$ : gearbox input torque $(\mathrm{N} \cdot \mathrm{m})$;

$\mathrm{T}_{\mathrm{gf}}$ : gearbox torque loss ( friction for example)(N・m );

$\mathrm{I}_{\mathrm{g}}$ : gearbox moment of inertia;

$\omega_{g i}:$ gearbox input rotational speed $(\mathrm{rad} / \mathrm{s}) ; \quad \omega_{g i n}=\omega_{g o} i_{g}$

$\mathrm{T}_{\text {gi: }}$ gearbox moment of inertia $(\mathrm{N} \cdot \mathrm{m}), T_{g i}=I_{g} \frac{d \omega_{g i}}{d t}$;

$i_{g}$ : gearbox transmission ratio.

Mathematical model of gearbox for rotational velocity changes

$\omega_{\text {gin }}=\omega_{g o} i_{g}$

In formula,

$\omega_{\mathrm{go}}$ : gearbox output rotational velocity $(\mathrm{rad} / \mathrm{s})$

\section{Dynamic Characteristics Modeling and Simulate Analysis of Chassis Transmission System of Felling \& Cultivation Machine}

\subsection{The Method of Transmission System Model for Force Transmission of Felling and Cultivation Machine Chassis}

Forward and backward simulate analysis are the frequently used method for simulation process of chassis transmission system, as shown in Figure 3-1. 


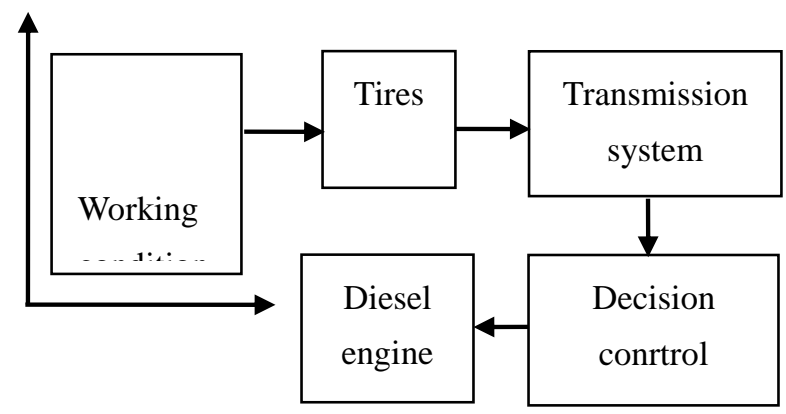

Figure 3-1. Simulation Process of Chassis Transmission System

Driver model is unnecessary in backward simulate analysis, torque and rotational speed required by wheels are determined at first in the model system under the given condition, then from layer to layer the actual torque and rotation of each part in the transmission system can be calculated from the corresponding sub system. As the actual torque and rotation are counted, the engine model can apply in computing the characteristics of fuel consumption and exhaust emission.

In this structure, the torque for driving vehicle is calculated in real-time of every time-step according to the demand of operation cycle, and then pass on the calculation along the opposite direction of the practical torque transfer path. According to the determined energy management strategy, the controller transfers power that needed for vehicle to power source by the form of requirement value after distributed, thus control realized.

Backward simulate structure mainly use simplified calculation method of look-up table due to its characteristics of reverse-direction calculation, which enable transmission system simulate model established on a kind of quasi-static base, and ignore the transient state change process of power transmission system in practical, which reduce the requirement for integral. As the low-order solver is generally applied in emulation calculation (e.g., Euler formula method), corresponding calculation with larger step is chosen, which may increase the simulation efficiency.

This paper selects backward simulation method base on the test condition of project.

According to the mathematical model framework of transmission system of Felling \& Cultivation machine chassis, simulation model of chassis transmission system is established in MATLAB/ Simulink in this paper. The model consists of three independent modules include: diesel engine, hydraulic torque converter and mechanical gearbox. Hydrodynamic transmission system of Felling \& Cultivation Machine chassis is connected according to the interface relationship between various parts as shown in Figure 3-2

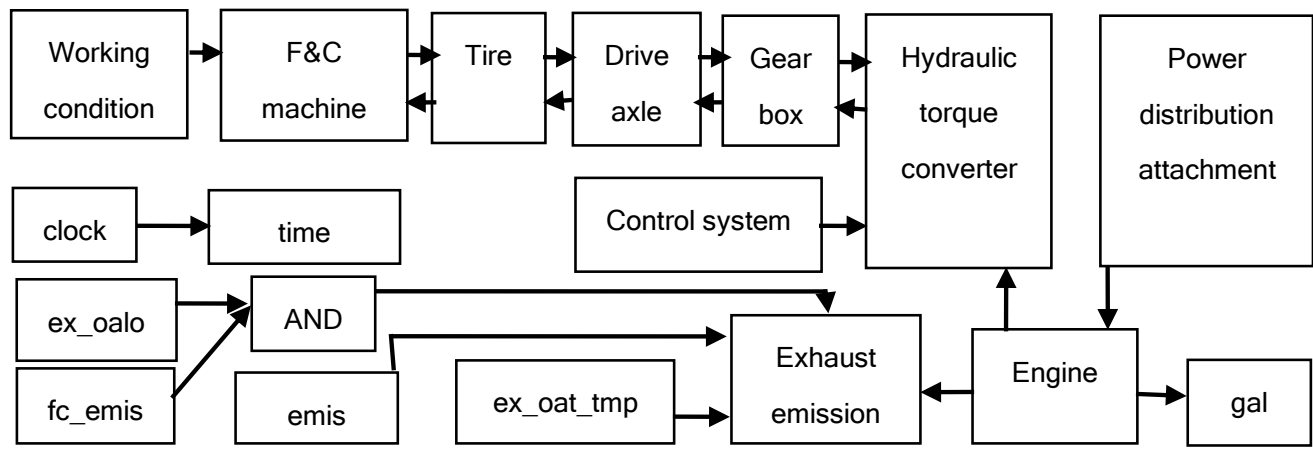

Figure 3-2. Transmission System Simulation Model of WCFJ30-I 


\subsection{Diesel Engine Model}

Output torque and rotational speed of engine are simulated with engine model according to the input value include specified working condition signals of engine, throttle signals and feedback vehicle speed, its model is shown in Figure 3-3.

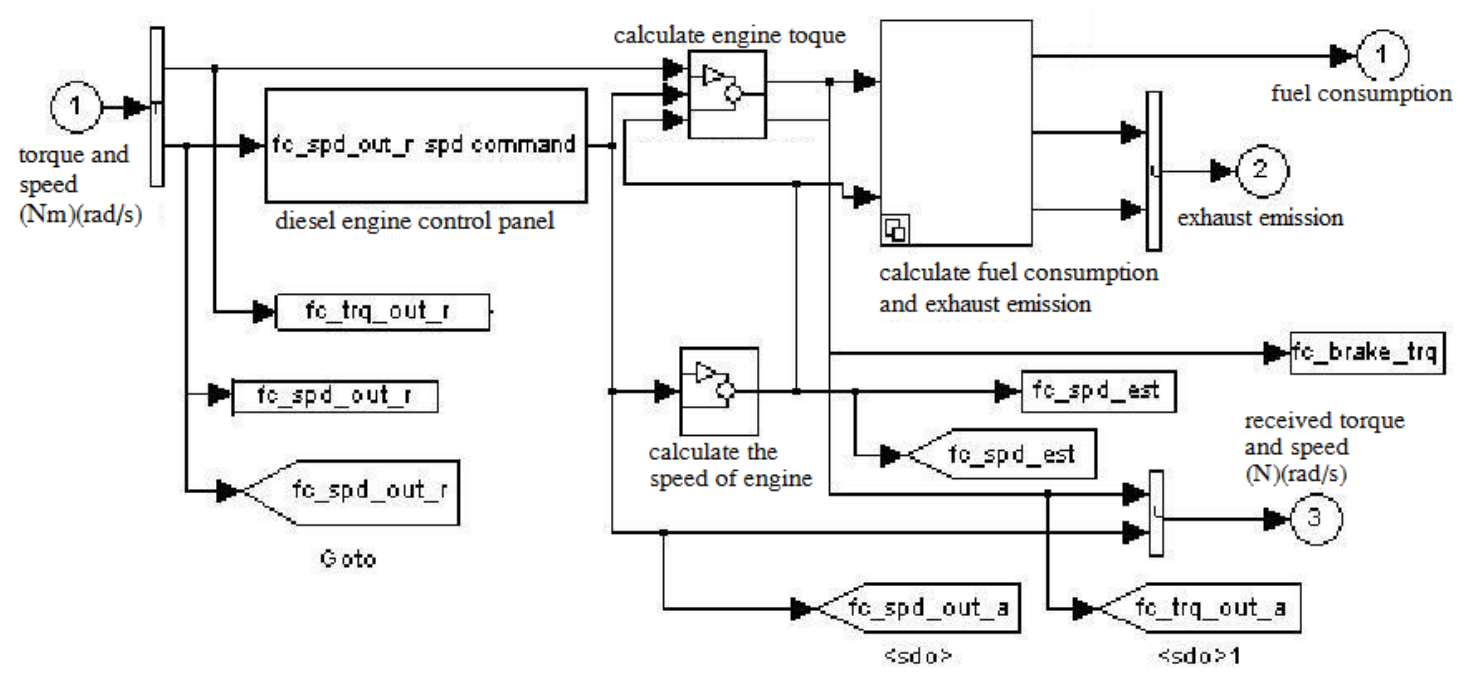

Figure 3-3. Engine Model

Sub-module of engine torque calculation is shown in Figure 3-4.

Sub-module of engine rotational speed calculation is shown in Figure 3-5.

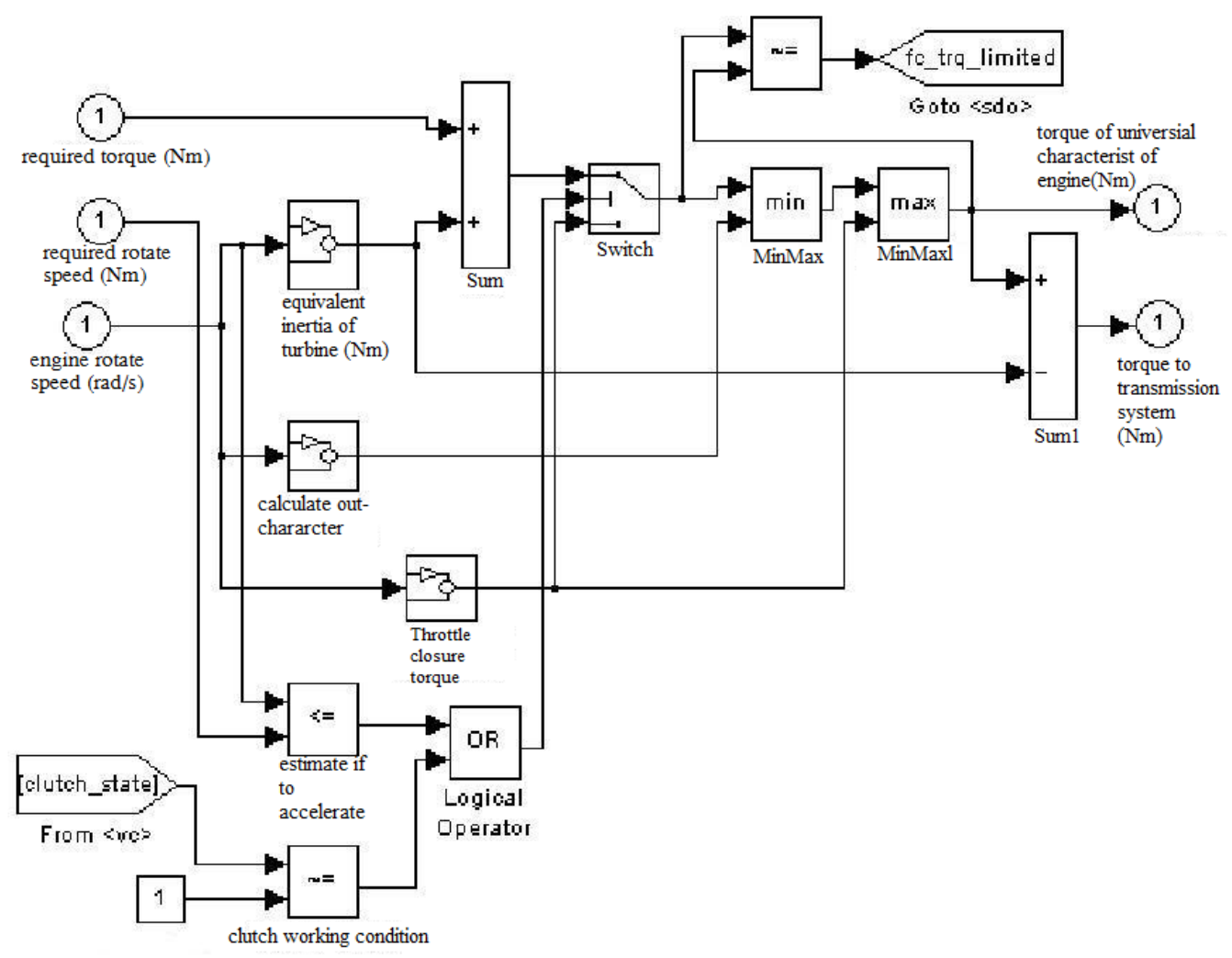

Figure 3-4. Sub-module of Engine Torque Calculation 


\subsection{Hydraulic Torque Converter Model}

The function of hydraulic torque converter model is to calculate the torque and rotational of engine transmission power by receiving the output power signals of engine, and simulate the role of hydraulic torque converter for automatic step-less speed change and torque converting when the hydraulic torque converter at the certain rotational speed range, according to the driving resistance variation and operation resistance variation (Hrovat.D. 1985).

Shifting torque sub-module need to be added to the hydraulic torque converter module, to make the hydraulic torque converter to identify shifting control system command, and determine the output torque value of turbine, the model is shown in Figure 3-6.

\subsection{Gearbox Model}

The main function of gearbox model is to simulate the gearbox control system, shifting is operated according to the requirement of Felling \& Cultivation Machine working condition, taking account of energy loss and moment of inertial loss such as mechanical friction and so on, it change the torque and rotational speed which is transmitted from engine to drive wheel (Dong, Y, 2002) as shown in Figure 3-7.

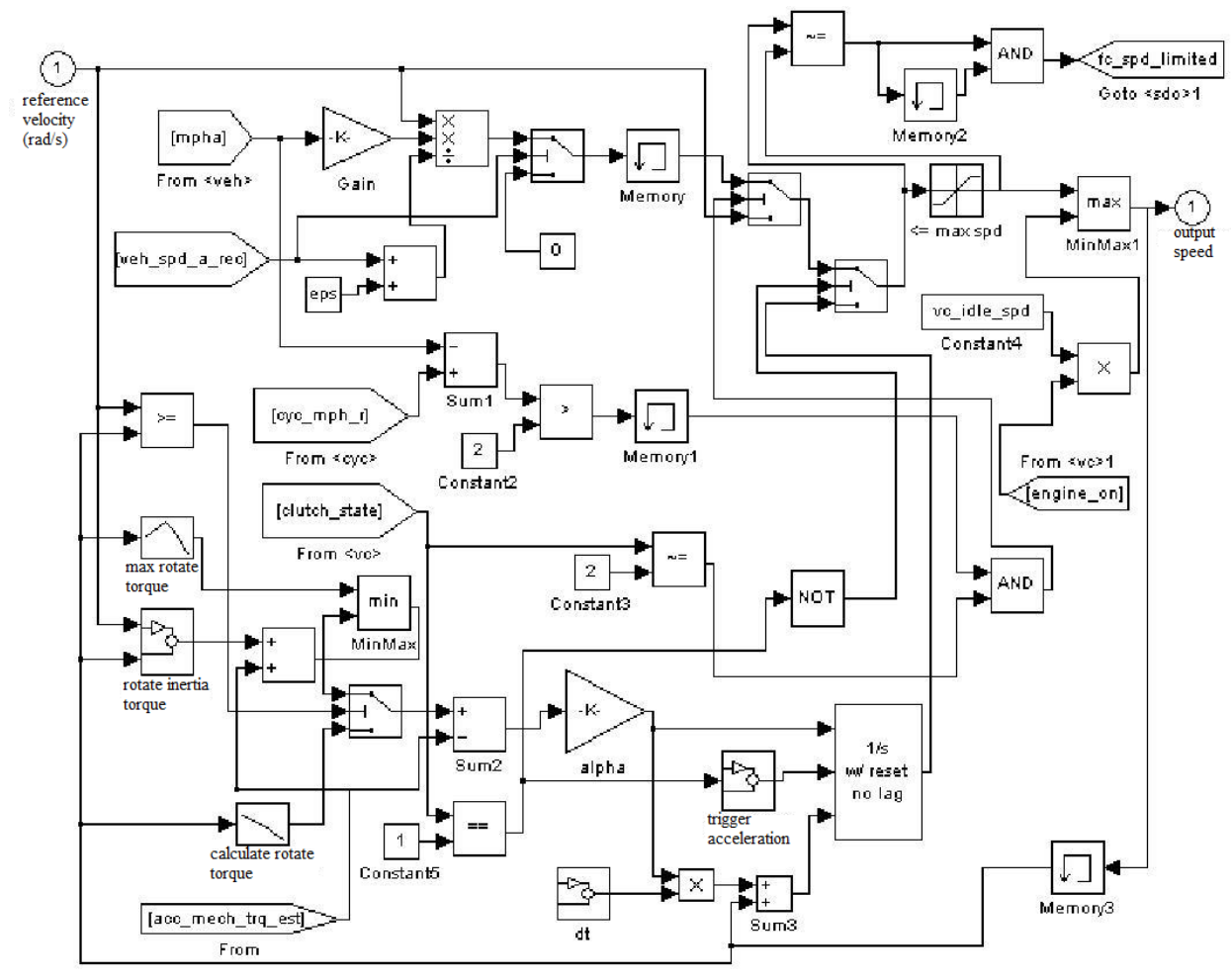

Figure 3.5. RPM Computing Submodule 


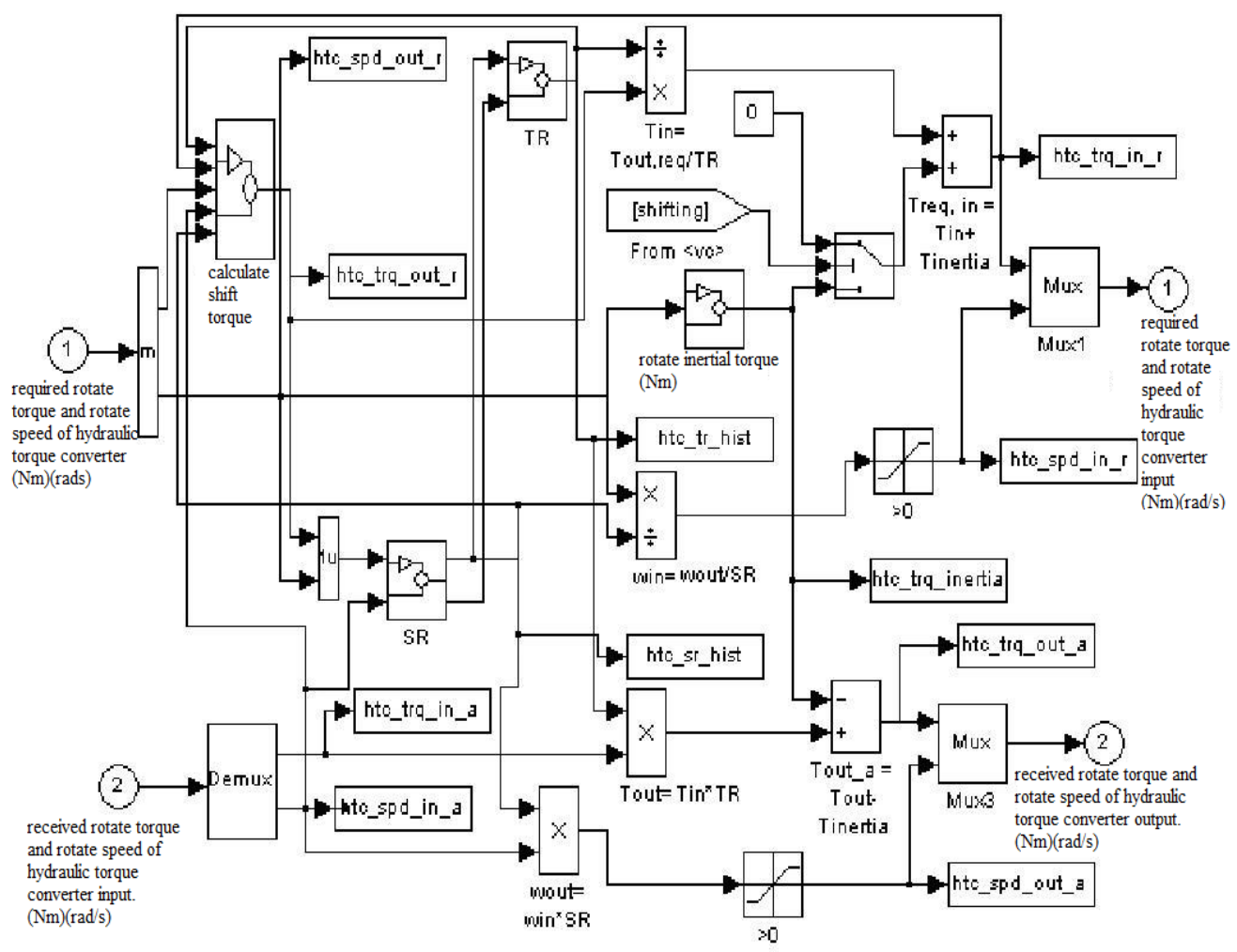

Figure 3-6. Hydraulic Torque Converter Model

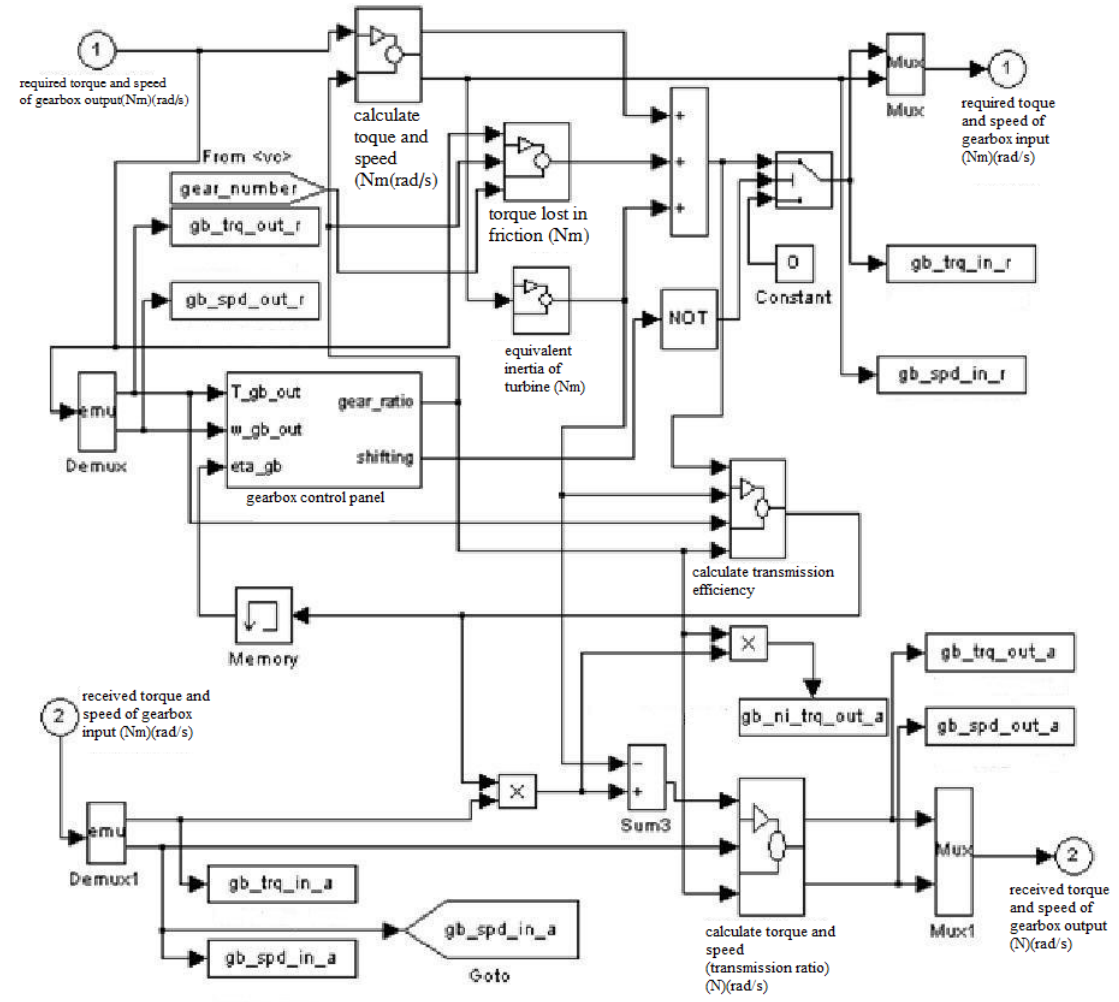

Figure 3-7. Transmission Model 


\subsection{Dynamic Simulation Analysis for Transmission System of Felling \& Cultivation}

Based on the transmission model in this paper, taking the parameter of the power system of WCFJ30-I Felling \& Cultivation machine chassis, simulation analysis for chassis is carried out through MATLAB/ Simulink software when the working condition are forward first gear, forward second gear and backward first gear respectively, then contrast between the actual measurement curve and simulation curve for chassis.

Some parameters in each model are adopted directly from existed results which shared by researcher who use the same device, others are from transmission system models and actual measurement data provided by related project units.

The result of comparison analysis is shown in Figure 3-8 to 3-13.

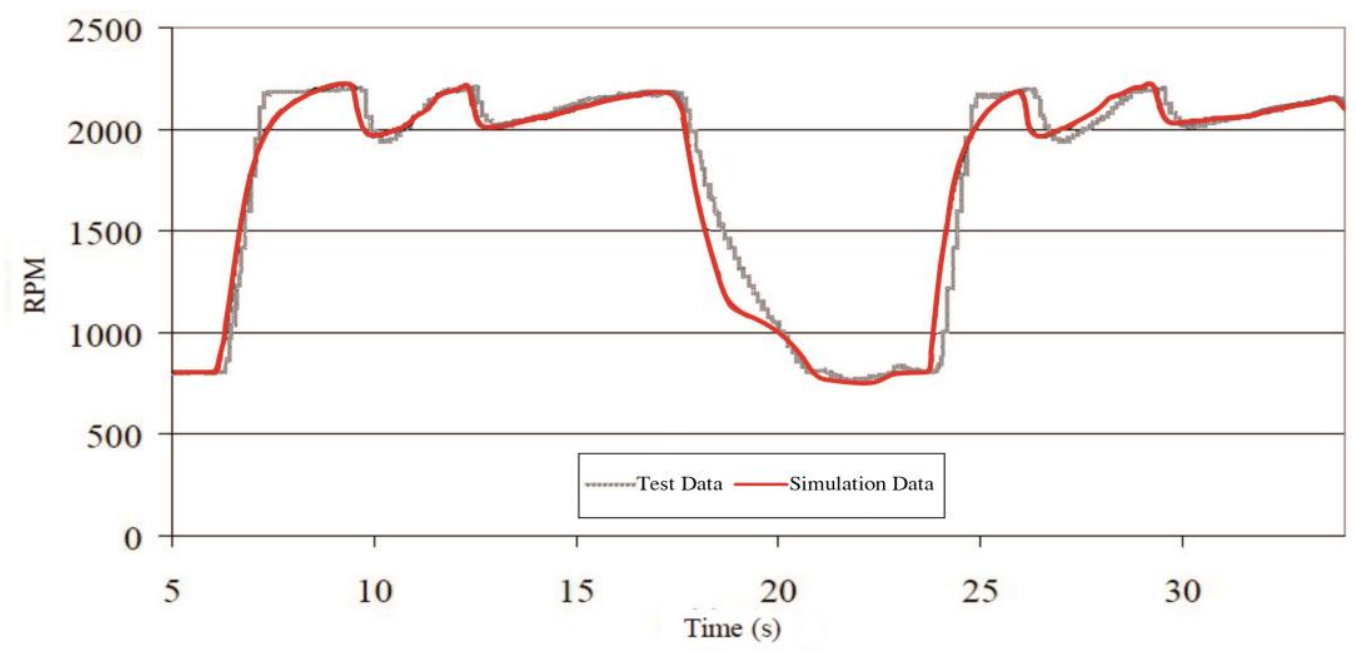

Figure 3-8. Engine RPM for Acceleration Run 1

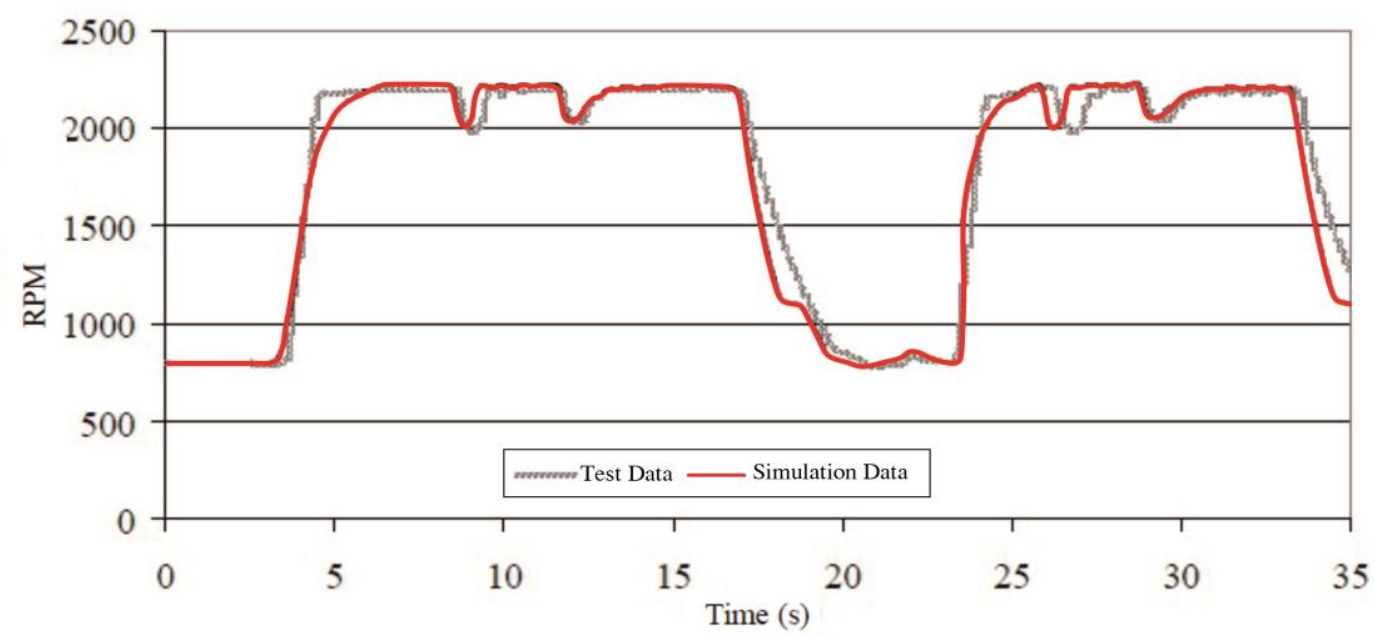

Figure 3-9. Fore/Aft Acceleration for Acceleration Run 1 


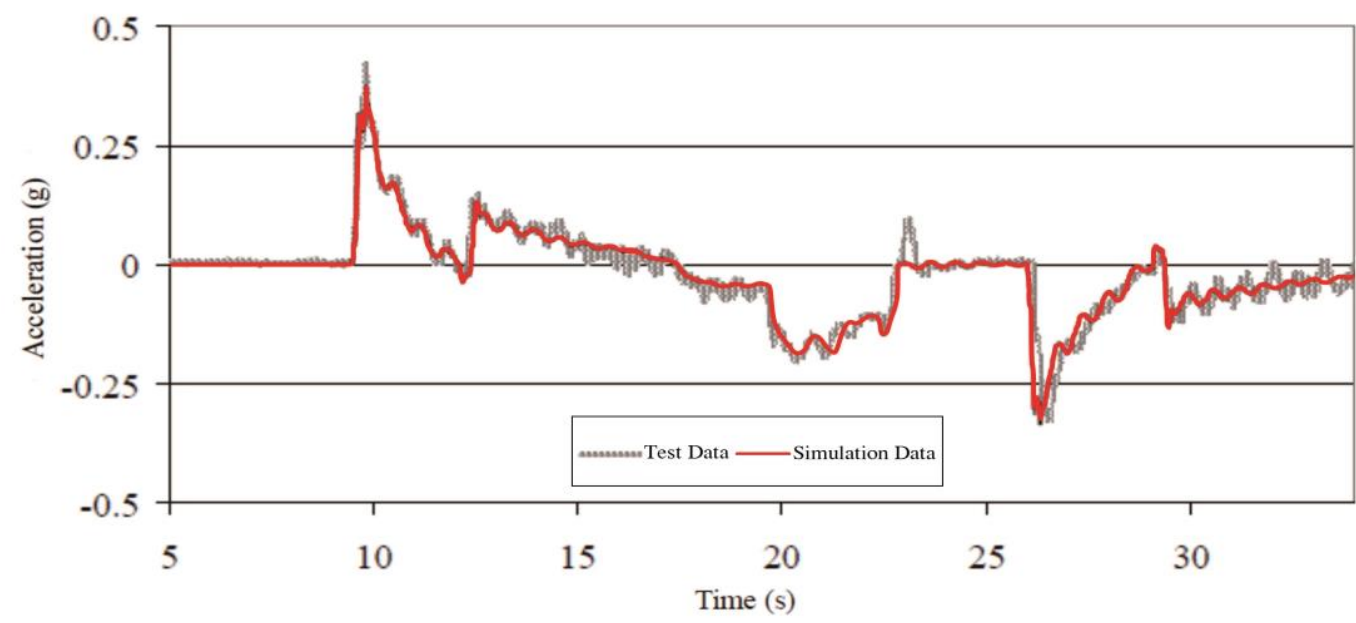

Figure 3-10. Engine RPM for Acceleration Run 2

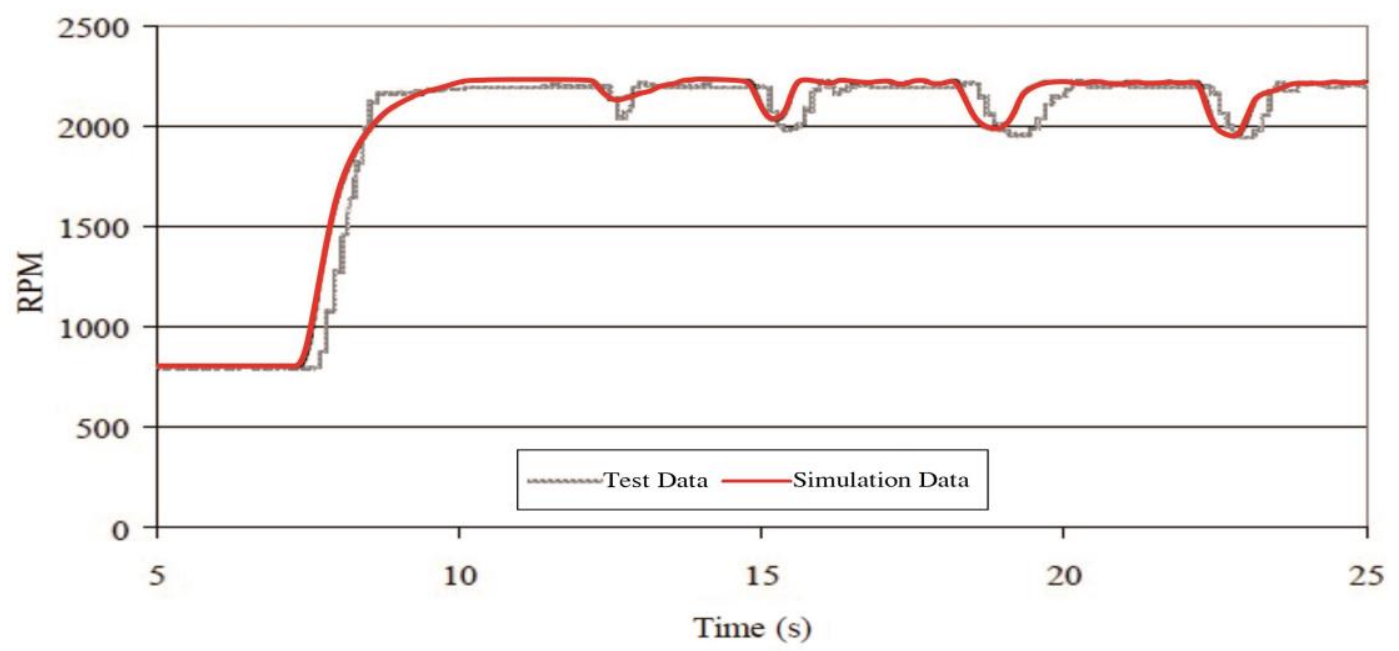

Figure 3-11. Fore/Aft Acceleration for Acceleration Run 2

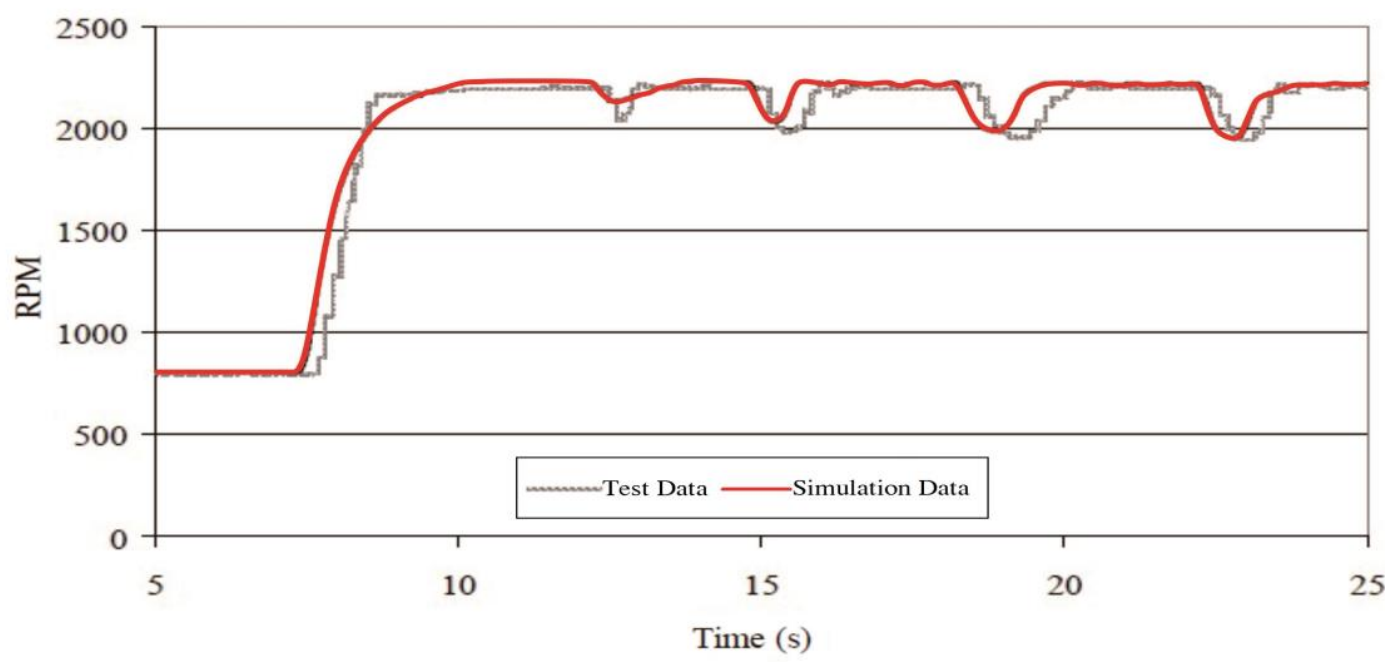

Figure 3-12. Engine RPM for Reversal 


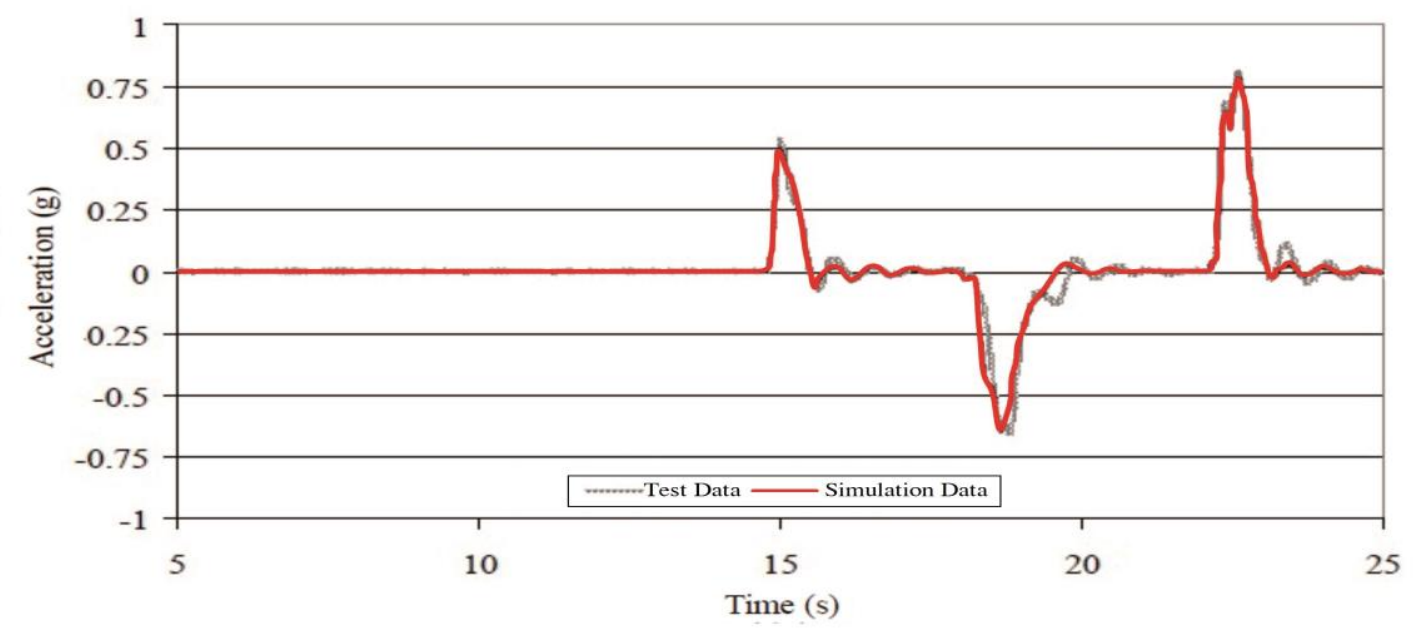

Figure 3-13. Fore/Aft Acceleration for Reversal

It can be seen from Figure 3-8 to Figure 3-13 though there are certain error between simulation result and actual measurement result, most of them are basically consistent with each other, while the sudden change of waveform is caused by throttle variation when testing, furthermore, the period of time of simulation testing is the same with the actual measurement, from which indicates that the simulation program has accuracy that is established based on mathematical model.

The engine rotational speed error at different shift is caused by the mathematical model error of engine external characteristics, the total torque error of transmission shaft is caused by ignoring the small power split on other parts of engine, simulation acceleration error is caused by ignoring the shifting operation time in simulation calculation.

\section{Conclusions}

1. In this paper, mathematical methods are used to establish mathematical models of each part of Felling \& Cultivation machine chassis transmission system, then divide the Felling \& Cultivation Machine chassis transmission system into several independent composing units base on that model.

2. Using adopting backward simulation method, which based on MTLAB/ Simulink software, to establish each part of dynamic simulation model of Felling \& Cultivation Machine chassis transmission system, then combining each model to an entire dynamic simulation model of chassis transmission system.

3. Take MCFJ30-I for instance, simulate analyze the transmission system by utilizing MCFJ30-I as input values, then contrast the chassis actual measurement data to confirm its reliability and practicability.

\section{Acknowledgements}

The authors wish to acknowledge the support of postdoctoral scientific research funds (049-0010) of Centre South University of Forestry and Technology in Hunan, China; Plan project (postdoctoral scientific research funding project of Hunan, 2013RS4049) of Science Department of Hunan Province, China; Youth Fund Project of Centre South University of Forestry and Technology in Hunan, China. 


\section{References}

[1] P. Haibing and L. Jinhao, "Ride Comfort Reserach on the Multifunctional Harvester and Dynamical Simulation", vol. 6, (2009), pp.8-5.

[2] L.V. Chang, G. Wang and Z. Yingshuang "Development of Simulation Module for Performance of Toruqe-converter Based on ADVISOR Software", Journal of System Simulation, vol. 18, no. 12, (2006), pp. 3396-3398.

[3] H. Qingquan and C. Ying, "Virtual Prototyping Simulation for the Coordinated Work of Engine and Torque Converter", Transactions of Beijing Institute of Technology, vol. 24, no. 1, (2004), pp. 40-44.

[4] L. Lishun, M. Xiangde and Z. Juanqing, "Basic Method of Virtual Design and Motion Simulation of Mechanical System Based on SoliWorks", Hoisting and Conveying Machinery, vol. 3, (2007), pp. 21-23.

[5] Y. Dong, V. Korivi, P. Attibele, Y. Yuan, "Torque Converter CFD Engineering Part I:Torque Ratio and K Factor Improvement Through Stator Modifications", SAE TechnicalPaper Series, (2002).

[6] D. Hrovat, W.E. Tobler, "Bond Graph Modeling and Computer Simulation of Automotive Torque Converters", Journal of the Franklin Institute, Pergamon Press Ltd. ,(1985), pp. 93-114.

[7] W. ZhanGuo, L. JinHao and W JiaD, "Application and Development of Artificial Intelligence Technology for the Data Management and Analysis in Forestry", International Conference on Artificial Intelligence and Computational Intelligence (AICI'09), (2009); Shanghai,China.

[8] H.C. German, "Real-Time Vehicle Subsystem Modeling and Simulation", M.S. Thesis, The University of Iowa, (2000).

[9] L.R. Johnson, D.L. Gochenour and C.J. Biller, "Simulation analysis of timberharvesting systems. Technical Paper", 23rd Annual conference and Convention of the American Institute of Industrial Engineers, (1972); Anaheim, CA.

[10] W. ZhanGuo, L. JinHao,Y. Ying, “The Design of Forestry Harvesting Machines Connecting Rod based on Finite Element Analysis", International Conference on Mechanical and Electrical Technology ICMET (2010); Singapore.

[11] "ADVISOR 2.0: A Second-Generation Advanced Vehicle Simulator for Systems Analysis"

[12] “NREL NAEVI'98”, Phoenix, AZ, (1998).

\section{Authors}

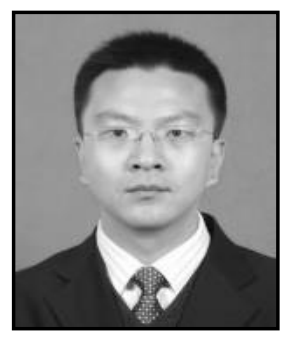

Zhanguo Wei, 1978-9. B.A degree in Automotive Engineering, Heilongiiang Institute of Technology in 1998. M.A.in Forestry Engineering, Northeast Forestry University in 2006. Ph.D. in Forestry Engineering, Beijing Forestry University in 2008. Majoring in Mechanical Engineering Design and Manufacturing by now.

Now he is working in Central South University of Forestry and Technology, Changsha city of Hunan Province, China, as associate professor. And his publishers are listed as followed:

[1] Liu JinHao, Wei ZhanGuo, Application of PLC in Control of Stacking Crane in Simulative Automated Storage and Retrieval System [J]. Forest Engineering,2007,23(5): 33 35.

[2] Wei ZhanGuo, Liu JinHao, The Virtual Design and Motion Simulation of the Robot of Excavating Tree Stump Based on SolidWorks [J]. Forestry Machinery \& Woodworking Equipment, 2007, 25(11): 43 45.

So far his research interests are Mechanical Engineering Design and Manufacturing and Forestry Special Robots. Dr. Wei has received these awards in followed:

2008-2009, 2009-2010 The outstanding postgraduate of Beijing Forestry University.

2008-2009, 2009-2010 The excellent academic award of Beijing Forestry University.

2008-2009, 2009-2010 The scholarship for outstanding postgraduate of Beijing Forestry University. 


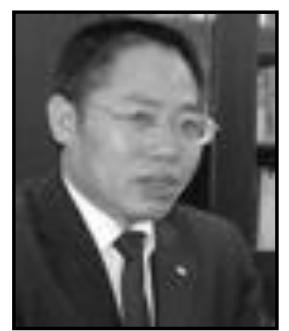

Wang Zhongwei, 1965-7. Receving B.A degree in Forestry Engineering, Central South University of Forestry and Technology in 1987. M.A in Forestry Engineering, Central South University of Forestry and Technology in 1990. Ph.D in Management Science and Engineer, Huazhong University of Science and Technology in 2004. Majoring in Engineering Project Management and Logistics and Supply Chain Management by now.

$\mathrm{He}$ is the President of School of Transportation and Logistics, Central South University of Forestry and Technology. Publishers are listed as followed:

[1]WANG Zhong-wei, KANG Yi-xiong. Research on Coordination Mechanism of Decentralized Assembly Furniture Supply Chain[J]. Communication in Computer and Information Science,2011,Vol.153(5):pp301-307.

[2]WANG Zhong-wei.Agricultural Products of Logistics Operation Mode Based on Transaciton Cost Theory[J]. Journal of Central South University of Forestry \& Technology,2009,07:70-71.

so far his research interests are Logistic System Organization and Logistics Engineering and Equipment.

Dr. Wang now is the Vice Director of Chian Forestry Engineer Society. Vice President of Hunan System Engineer and Management Association. Vice Director of Human System Engineering and Management Association.

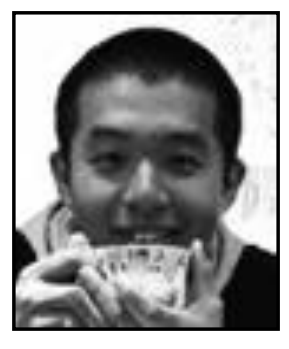

Zhou Zhuoxian, 1992-11. B.A undergraduate students in Central South University of Forestry and Technology. Majoring in Forestry Engineering by now.

Mr. Zhou received following awards:

2011 2012 The Merit Student of Central South University of Forestry and Technology.

2012 2013 Third grade scholarship of Central South University of Forestry and Technology. 
International Journal of Multimedia and Ubiquitous Engineering

Vol. 10, No. 3 (2015) 